\title{
BMJ Open Maternal body mass index and the prevalence of spontaneous and elective preterm deliveries in an Irish obstetric population: a retrospective cohort study
}

Angela Vinturache, Aoife McKeating, Niamh Daly, Sharon Sheehan, Michael Turner

To cite: Vinturache $A$, McKeating A, Daly N, et al. Maternal body mass index and the prevalence of spontaneous and elective preterm deliveries in an Irish obstetric population: a retrospective cohort study. BMJ Open 2017;7:e015258. doi:10.1136/ bmjopen-2016-015258

- Prepublication history for this paper is available online To view these files please visit the journal online (http://dx.doi org/10.1136/bmjopen-2016015258).

Part of this work was submitted as an abstract to the 63rd Annual Meeting of Society of Gynecologic Investigation 2016, Montreal, Canada.

Received 25 November 2016 Revised 19 July 2017

Accepted 17 August 2017

\section{CrossMark}

Centre for Human Reproduction, University College Dublin, Coombe Women and Infants University Hospital, Dublin, Ireland

Correspondence to

Dr Angela Vinturache;

angela_wintu@shaw.ca

\section{ABSTRACT}

Objective To estimate the association between maternal body mass index (BMI) and risk of spontaneous preterm delivery (SPTD) and elective preterm delivery (ePTD) in singleton and multiple pregnancies.

Design Retrospective cohort study.

Setting Electronic records of all deliveries from 2009 through 2013 in a tertiary university hospital were abstracted for demographic and obstetrical information. Participants A total of 38528 deliveries were included. Participants with missing data were excluded from the study. BMI was calculated from the measurement of height and weight at the first prenatal visit and categorised. Sonographic confirmation of gestational age was standard. Outcome measures Primary outcomes, SPTD and ePTD in singleton and multiple pregnancies, were evaluated by multinomial logistic regression analyses, stratified by parity, controlling for confounding variables.

Results Overall rate of PTD was $5.9 \%$, from which $2.7 \%$ were sPTD and $3.2 \%$ ePTD. The rate of PTD was $50.4 \%$ in multiple pregnancies and $5.0 \%$ in singleton pregnancies. The risk of SPTD was increased in obese nulliparas (adjusted $\mathrm{OR}(\mathrm{aOR}) 2.8,95 \% \mathrm{Cl} 1.7$ to 4.4 ) and underweight multiparas (aOR 2.2, 95\% $\mathrm{Cl} 1.3$ to 3.8). The risk of ePTD was increased in underweight nulliparas (aOR 1.8; 95\% Cl 1.04 to 3.4) and severely obese multiparas (aOR 1.4, 95\% Cl 1.02 to 3.8). Severe obesity increased the risk of both SPTD (aOR 1.4; 95\% Cl 1.01 to 2.1) and ePTD (aOR 1.4; $95 \% \mathrm{Cl} 1.1$ to 1.8 ) in singleton pregnancies. Obesity did not influence the rate of either SPTD or ePTD in multiple pregnancies.

Conclusion Maternal obesity is an independent risk factor for PTD in singleton pregnancies but not in multiple pregnancies. Obesity and nulliparity increase the risk of SPTD, whereas obesity and multiparity increase the risk of ePTD.

\section{INTRODUCTION}

Preterm delivery (PTD), defined as delivery prior to 37 weeks of gestation, is the main cause of perinatal mortality and morbidity worldwide. ${ }^{1}$ It is associated with high rates of interventions and specialised obstetrical and neonatal care, and long-term disability of the offspring, which in turn leads to increased
Strengths and limitations of this study

- This study ascertained obesity-attributable spontaneous and elective preterm deliveries stratified by parity and plurality.

- The study used a large obstetrics cohort representative for the Irish population, inclusive of all socioeconomic strata across the urban-rural divide.

- Increased accuracy and reliability of the data by objective measures of maternal anthropometrics and standard sonographic confirmation of gestational age in all women.

- No detailed information on obstetrical history was available for this study.

emotional costs for families and financial costs for families and society. ${ }^{23}$

Evidence from systematic reviews and meta-analyses demonstrates that the risk of PTD is influenced by both individual and socioeconomic factors. ${ }^{4-14}$ Among these, the role of maternal body mass index (BMI) in the complex interplay of biological, behavioural and socioeconomic determinants of preterm birth is not fully understood and the debate on the relationship between maternal BMI and spontaneous preterm delivery (sPTD) or elective preterm delivery (ePTD) is ongoing. Both low and increased BMIs have been associated with risk of adverse pregnancy and perinatal outcomes. Whether the continuum of overweight and obesity is associated with increased, decreased or neutral risks on the length of gestation is uncertain. ${ }^{45-18}$ The same holds true for the association between maternal underweight and preterm birth. ${ }^{518}$ The discordance in opinions may reside with different characteristics of various populations, and with interpretation of the findings, which in most studies is hindered by the uncontrolled or residual confounding such as parity, plurality, socioeconomic and 
smoking status, access to antenatal healthcare, among others.

PTD is common in multiple pregnancies, with $55 \%$ of multiple births being delivered before 37 weeks' gestation, compared with the rate of $6 \%-10 \%$ in singleton pregnancies. ${ }^{1920}$ The incidence of multiple pregnancies has increased over past decades, mainly due to increase in assisted reproduction ${ }^{21}$. While multiple factors contribute to the increased rates of PTD in multiple pregnancies, the independent role of maternal obesity as a risk factor for either ePTD or sPTD remains uncertain. ${ }^{22} 23$

The incidence of obesity is increasing among women of childbearing age, approximately $60 \%$ of women entering pregnancy being overweight or obese in the USA. ${ }^{24} 25$ Similar trends are observed in Ireland, ${ }^{2627}$ where the incidence of overweight and obesity was reported of approximately $44 \%,{ }^{28}$ with a rate of obesity in first trimester of pregnancy between $19 \%$ and $25 \%$ at the first prenatal visit. $^{29} 30$ With rates of obesity in developed countries continuing to rise, it is imperative to understand the complex patterns of associations between maternal obesity and risk of PTD in nulliparous and multiparous women, singleton and multiple pregnancies, in order to develop targeted, effective lifestyle and therapeutic interventions for women at risk of PTD.

Using the data collected prospectively in the electronic health records from labour and delivery in a tertiary maternity hospital, the aim of this study was to examine the association between maternal BMI and the risk of sPTD and ePTD in singleton and multiple pregnancies, and in nulliparous and multiparous women.

\section{METHODS}

\section{Study population}

The study included all women who delivered a baby weighing $\geq 500 \mathrm{~g}$ at a tertiary referral university teaching hospital between 1 January 2009 and 31 December 2013. The hospital, Coombe Women and Infants University Hospital Dublin, is one of the largest maternity hospitals in the European Union. The hospital population includes all socioeconomic strata across the urban-rural divide, including women with both public and private health insurance. Data from antenatal care, labour and delivery were collected prospectively and recorded electronically. Anthropometric, sociodemographic and clinical information at the first prenatal visit ('booking visit') was recorded by trained midwives and the information from labour and delivery was abstracted from medical records by administrative staff. Gestational age was confirmed for all women by ultrasound scanning at the booking visit. The use of anonymised data set for research purposes was granted by the Coombe Women and Infants University Hospital Research Ethics Committee (ref 004-013). Accuracy of the data was validated by the IT Department and the Master's Office for the Annual Clinical Report.

\section{Variable definitions}

The gestational age at delivery provided in the data set was dichotomised into term and preterm deliveries. The main outcome variable, PTD, was defined as a birth occurring before $36^{+6}$ weeks' gestation inclusive. Term delivery was defined as a birth occurring between $37^{+0}$ and $41^{+6}$ weeks' gestation. Further, PTD was categorised into spontaneous and elective preterm births. An sPTD was defined as a birth in which spontaneous onset of labour was documented. An ePTD was defined as a medically indicated, provider-initiated birth in which the labour was either induced or the woman was delivered by elective caesarean section (CS).

BMI was calculated as the ratio of weight $(\mathrm{kg})$ divided by height squared $\left(\mathrm{m}^{2}\right)$ from the standardised measurement of height and weight at the first prenatal appointment (first trimester of pregnancy) by trained midwives. Women were divided into five groups according to the categories defined by the WHO's classification as follows: underweight (BMI $\left.\leq 18.49 \mathrm{~kg} / \mathrm{m}^{2}\right)$, normal weight (BMI $18.50-24.99 \mathrm{~kg} / \mathrm{m}^{2}$ ), overweight (BMI 25.00-29.99 kg/ $\mathrm{m}^{2}$ ), obese class I (mildly obese) (BMI $30.00-34.99 \mathrm{~kg} / \mathrm{m}^{2}$ ), obese class II (moderately obese) (BMI $35.00-39.99 \mathrm{~kg}$ / $\mathrm{m}^{2}$ ) and obese class III (severely obese) (BMI $\geq 40.00 \mathrm{~kg}$ / $\mathrm{m}^{2}$ ). For meaningful comparisons, the obesity class II and class III were collapsed in one category of moderately/ severely obese women $\left(\mathrm{BMI}>35.00 \mathrm{~kg} / \mathrm{m}^{2}\right)$.

All women were offered a routine dating scan at the first prenatal visit to confirm gestational age and to accurately determine the estimated date of confinement.

Attendance for prenatal care was defined as normal attendance for women with early booking for antenatal care (before 10 weeks' gestation) and regular attendance to appointments with the healthcare provider, and poor attendance for women who were late bookers (after 20 weeks' gestation) and/or attended sporadically for their appointments.

Multiparity was defined as women who had a least one previous delivery of a fetus weighing $500 \mathrm{~g}$ or more. Multiple pregnancies included twin, triplet and quadruplet pregnancies. Advanced maternal age was considered age $\geq 35$ years at the time of attendance to prenatal care (11). We used self-reported nativity (European (Irish, non-Irish) and non-European (Afro-Caribbean, Asian, Hispanics)) to classify the ethnic and racial origin of women (12).

\section{Study design and methodology}

The inclusion criteria for the women in the study were: delivery before 42 weeks' gestation; live infant weighing $\geq 500 \mathrm{~g}$; singleton or multiple pregnancy. Multiple deliveries were counted once. Data for BMI were missing for 435 women, 318 women in the term deliveries group and 117 women in the preterm group. Women with missing BMI information were excluded from further analyses. Data for gestational age at delivery were missing for 34 women. Information on parity was available for all cases. Women who 
delivered at $\geq 42+0$ weeks' gestational age (post-term) were excluded from the study. From 42362 women in cohort, $2834(6.6 \%)$ were post-term. A total of 39 528 women were included in the study. For women with missing covariate, we handled the missing data by creating a categorical indicator variable $(1 / 0)$ for missing responses.

Information about pregnancy, labour and delivery was linked to information on newborn infant using unique identifiers (hospital numbers).

The main outcome of the study was PTD, which was examined as a composite variable including all PTD and separately as SPTD and ePTD. The rates of PTD were assessed in nulliparous and multiparous women, and in singleton and multiple pregnancies, stratified by maternal BMI at first antenatal visit, controlling for confounders: maternal age, nativity, maternal occupation, smoking status, parity, attendance to antenatal care, multiples, congenital anomalies.

\section{Statistical analyses}

Descriptive statistics were produced for sociodemographic, clinical characteristics and outcome variables for all women. Continuous data were presented as mean $\pm \mathrm{SD}$. Categorical data were expressed as frequency distributions. Univariate analyses assessed associations between sociodemographic and obstetrical characteristics and perinatal outcomes of interest using $\chi^{2}$ test and logistic regression. Student's t-test assessed the difference between groups for continuous variables. Multinomial logistic regression analyses were conducted to investigate the association between non-optimal body weight and the subtypes of preterm birth stratifying by parity and type of pregnancy, controlling for the effect of confounders. The statistical models were fitted to the data using a forward stepwise model strategy which introduced a block of demographic variables (maternal age $(\leq 34$ years old, $>35$ years old), nativity (European, non-European), occupation (employed, non-employed), smoking status (smoker, non-smoker)), followed by a block of obstetrical variables (parity (nullipara, multipara), attendance to prenatal care (normal attendance, poor attendance), number of fetuses in the index pregnancy (singleton, multiples), congenital anomalies (yes, no)). The model performance was assessed using goodness of fit, the Cox and Snell, Nagelkerke and McFadden pseudo R2 measures, and the likelihood ratio tests. To assess the effect on PTD of the relationship between the dependent variables BMI, parity and multiples, level of interaction has been tested in the regression models. Additional analyses compared the sociodemographic, lifestyle and clinical characteristics of term and preterm deliveries.

ORs and 95\% CIs were calculated for final models. All statistical analyses were performed using the SPSS for Windows package, V.20 (IBM SPSS).
RESULTS

Of the 39528 deliveries, 37167 (94.0\%) were term and $2361(5.9 \%)$ were preterm. Of the preterms, 209 $(8.9 \%)$ were extremely preterm $(<28+0$ weeks' gestation $)$, $342(14.5 \%)$ were very preterm $(28+1$ to $31+6$ weeks' gestation) and $1810(76.7 \%)$ were moderate to late preterm (32+0 to 36+6 weeks). From PTD, 1075 (2.5\%) were sPTD and $1286(3.1 \%)$ were ePTD (table 1$)$.

Demographic and obstetrical characteristics of women with term and preterm deliveries, spontaneous and elective, are shown in table 1 . When compared with women who delivered at term, women with PTD were more likely to be of non-European nativity, older than 35 years, unemployed, nulliparous, had fertility treatments, or irregular attendance to prenatal care. Women from this group were also more likely to smoke, use illicit drugs and be exposed to domestic violence during pregnancy than women from term delivery group. Women with multiples were 19 times more likely to deliver preterm than women with singleton pregnancies. Women with PTD were five times more likely to deliver by emergency CS but less likely to be induced or have an instrumental vaginal delivery than women who delivered at term. Preterm infants were more likely to have been diagnosed with congenital anomalies.

When further compared the demographic and clinical characteristics between women with SPTD and EPTD, our data showed that women with SPTD were more likely to be younger than 35 years, smoke and use recreational drugs throughout pregnancy, conceive spontaneously, and carry a singleton pregnancy, and less likely to have a planned pregnancy than women with ePTD. Conversely, women with ePTD were more likely to be heavier, undergo fertility treatments, carry multiples, have a planned pregnancy and attend regularly prenatal care appointments than women with SPTD. The occurrence of either SPTD or ePTD was similar in women of European or non-European ancestry, Irish or non-Irish nationality, employed or unemployed. Both sPTD and ePTD occurred with similar frequency in nulliparous ( $46.0 \%$ and $44.4 \%$, respectively) and multiparous (54.0\% and $55.6 \%$, respectively) women.

Almost $70 \%$ of women with sPTD delivered vaginally, whereas only $20 \%$ of women from ePTD group delivered vaginally, with the rest requiring either elective (19.9\%) or emergency caesarean (60.0\%). As expected, most infants delivered preterm had a birth weight lower than $2500 \mathrm{~g}$ ( $64.2 \%$ of sPTD and $77.4 \%$ of ePTD). However, the infants from sPTDs were heavier and less likely to be diagnosed with congenital anomalies than babies resulted from ePTDs. More babies were spontaneously delivered by 28 weeks' gestation, whereas more elective deliveries occurred at gestational age of 28-32 weeks.

Table 2 shows the characteristics of women who delivered preterm stratified by BMI at the first antenatal visit. In our study, ePTD was more frequent in overweight $(58.3 \%)$, moderately $(64.4 \%)$ and severely obese women $(66.7 \%)$, whereas sPTD was more frequent in underweight women $(58.9 \%)(\mathrm{p}<0.001)$. 


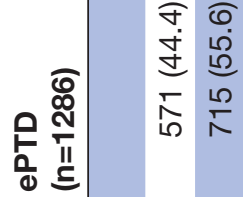

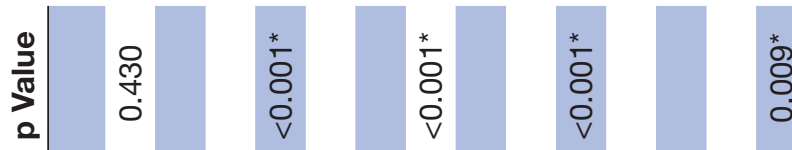

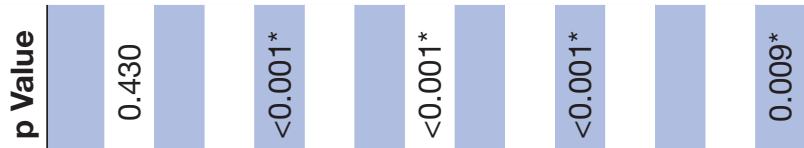

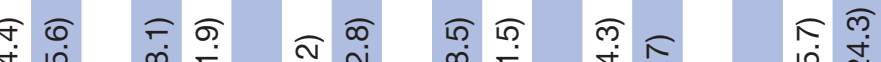

迎 ळ ल స

ஸे

๙ิ

$\stackrel{\infty}{\stackrel{N}{N}}$

응 $\stackrel{0}{\sim}$

वे है

囱

$\stackrel{\mathrm{s}}{\mathrm{s}} \stackrel{\mathrm{N}}{\mathrm{N}}$

, 点 $\frac{m}{2}$

กุ

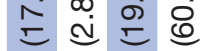

令

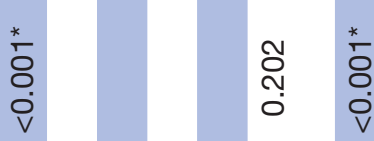

${ }^{*}$
$\dot{8}$
$\dot{0}$
$\dot{v}$

ธุด อิ สุ

过 过

in

कํ.

๑ุ

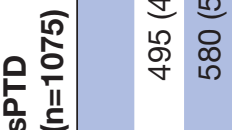

$\frac{m}{6}$ 获

i

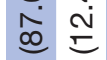

웅

ने

농

क

ग

ब्ल ल न बढ

กำ กิ

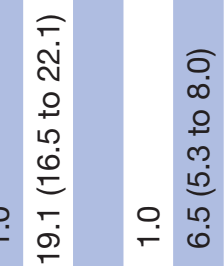

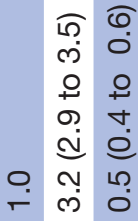

ஸ़े

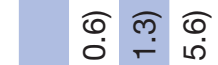

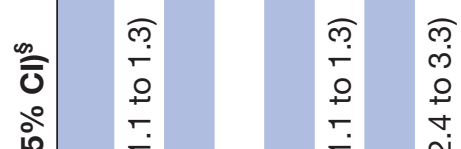

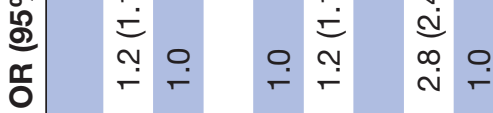

ลิ $\bar{\infty} \widehat{\infty}$

守 递

क त

ल)

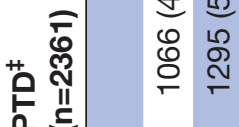

बै ले

侮

เอ क

กิ ต

๓)

कิ ลิ

$\stackrel{\text { N }}{\sim}$

令 ठ

ฮे

लू ले

เก กิ สุ

站过

答寺

กิ ส ฒุ

过

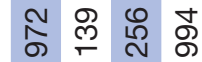

구일

욷둥

$\widehat{\sigma} \widehat{\sigma} \widehat{\sigma}$

+๘

का

ఠִ

¿

घ․ำ

$\stackrel{2}{\sim}$

ऽ

बุ

党 $匚$

ㅇำ ᄋิ

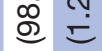

के 당

क्ल

क् ल

กิ ชิ

เृ

人ิ

ठำ

क के क़

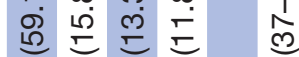

过

䒘永

ले

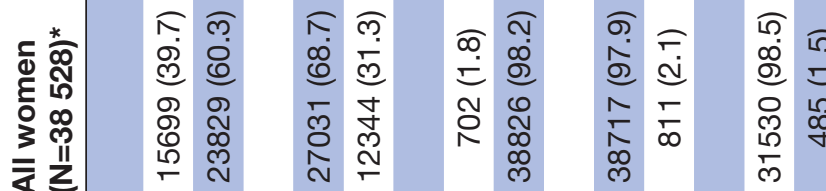

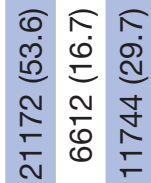

ศิ สุ ชิ

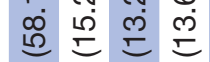

尔

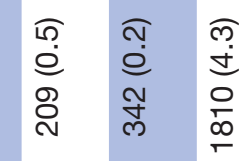

운

을.

N

N

心

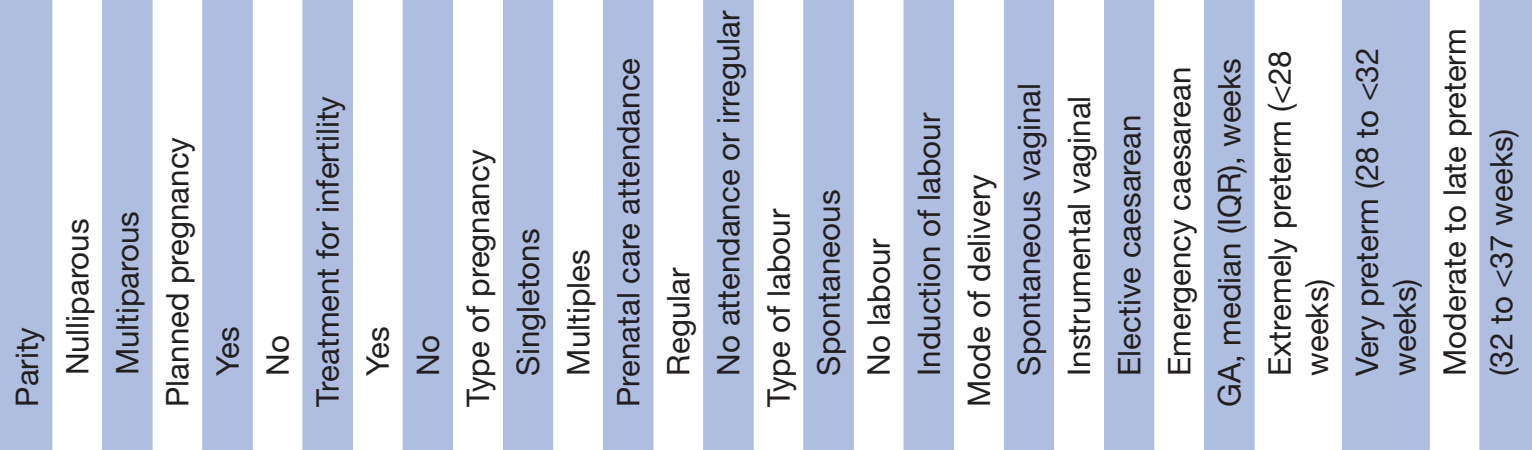


Prevalence of PTD was higher in overweight and obese multiparous than nulliparous women. In women with suboptimal BMI, the nulliparous women had a higher rate of PTD than underweight multiparous women. There was no difference in the prevalence of PTD in singleton and multiple pregnancies when stratified by BMI category.

The highest rate of PTD occurred in women in their $30 \mathrm{~s} ; 31.1 \%$ in women aged $30-34$ years, and $24.1 \%$ in women aged 35-39 years. In both these age groups, PTD rate was higher in overweight and obese women than in normal weight women. Women younger than 20 had the lowest incidence of PTD (4.1\%). In this group, the occurrence of PTD was higher in underweight women $(10.7 \%)$ than in normal weight women $(6.2 \%)$. The majority of women who delivered preterm were of Irish ancestry in each BMI category $(p<0.05)$. For the women of non-Irish ancestry who delivered preterm, Asian women were more likely to be underweight whereas Afro-Caribbean women were more likely to be obese $(\mathrm{p}<0.001)$. For all BMI categories, the frequency of PTD was higher in women who performed semiskilled or unskilled manual work than in women with skilled manual or managerial jobs $(\mathrm{p}=0.024)$.

There was an association between the mode of delivery, Apgar scores and early pregnancy BMI in women who delivered preterm $($ all $\mathrm{p}<0.001)$. Obese women were more likely to deliver by CS, either elective or emergency, and less likely to undergo assisted vaginal delivery before 37 weeks' gestation. There was no difference in the maternal attendance to antenatal care, birth weight, presence of congenital anomalies and admission to intensive care between overweight or obese women and normal weight women who delivered preterm.

Table 3 shows the adjusted risk of sPTD and ePTD in women with non-optimal BMI, stratified by parity and type of pregnancy.

Multinomial analyses stratified by parity showed that in nulliparas, the odds of SPTD were almost threefold higher in moderate/severely obese (adjusted OR (aOR) $2.8,95 \%$ CI 1.7 to 4.4 ) and 1.5-fold higher in moderately obese women (aOR 1.5, 95\% CI 1.08 to 2.3 ) than in normal weight women. The risk of ePTD was increased by $80 \%$ in underweight (aOR 1.8; 95\% CI 1.04 to 3.4 ) as compared to normal weight nulliparas.

In contrast, in multiparous women, moderate/severely obese had a $40 \%$ higher risk of ePTD than women with normal weight (aOR 1.4, 95\% CI 1.02 to 3.8). Underweight multiparas had twice the risk of sPTD than normal weight women (aOR 2.2, $95 \%$ CI 1.3 to 3.8 ).

In the adjusted model stratified by type of pregnancy, moderate/severe obesity increased the risk of both sPTD (aOR 1.4; 95\% CI 1.01 to 2.1) and ePTD (aOR 1.4; $95 \%$ CI 1.1 to 1.8 ) in singleton pregnancies. Obesity did not influence the rate of either SPTD or ePTD in multiple pregnancies.

No interaction was observed between maternal BMI, parity and type of pregnancy, thus there were no additive effects of these variables on PTD. 


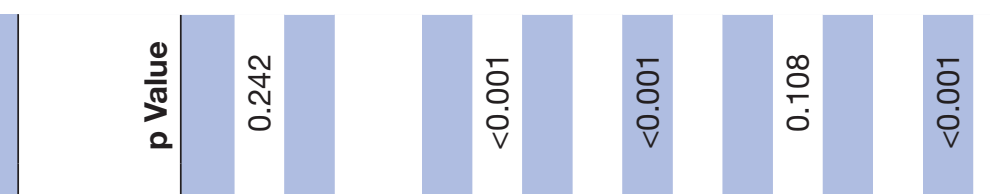

s

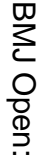

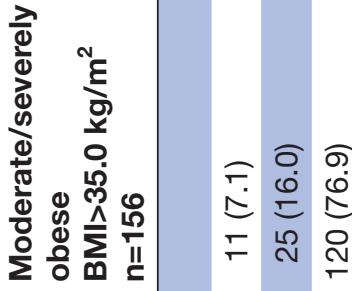

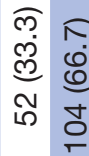

कุ สุ

เกิ เกต

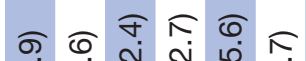

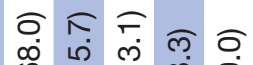

กิ

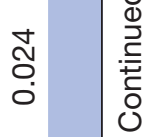

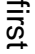

음

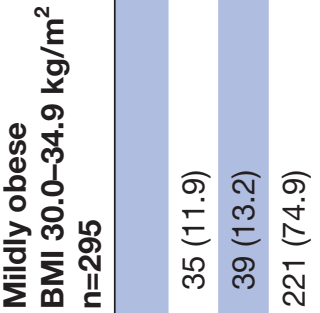

๙ึ

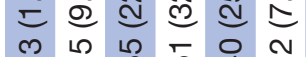

$\theta=50$

ㄷำ

离

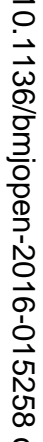

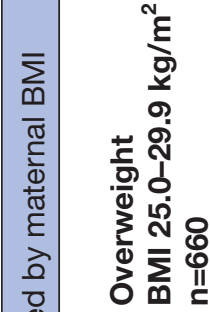

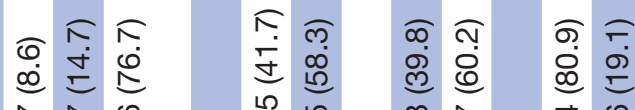

อิ

क्ष

$\widehat{0}$

శ্

๑)

岇

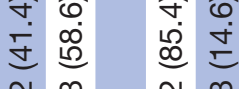

ชิ ণิ

过 占

识

ल

б. 宁

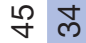

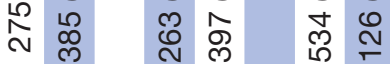

m

$\pm \simeq \varphi \dot{0}$

ฉ్ ำ

ले ळ

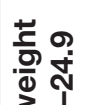

$\frac{10}{\infty} \infty$

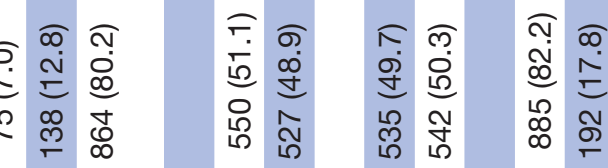

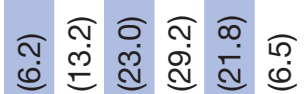

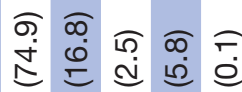

๑ุ

हैำ

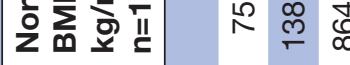

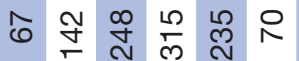

৪ 으

들

ल्లి

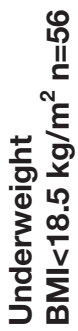

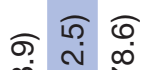

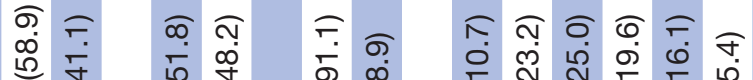

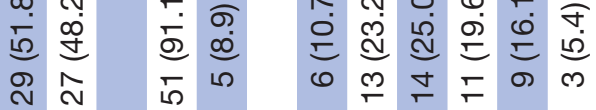

बִ

เִ

ले

냉으 $\sim$

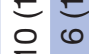

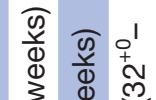

उ $\infty_{0}^{\infty}$

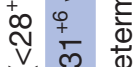

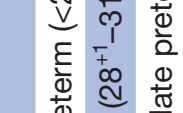

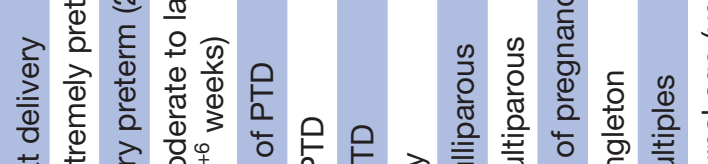

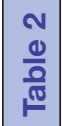

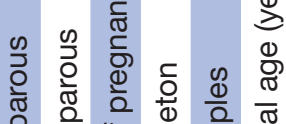

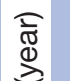

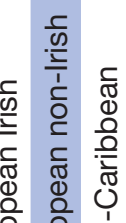

芩

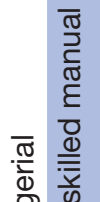

$\frac{0}{8}$

$\stackrel{\sim}{\stackrel{2}{*}}$

ำ

훙

룽

은.

ஓ

웅

을

\%

กิ

$\stackrel{2}{0}$

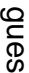

물

ه্]

임

을 


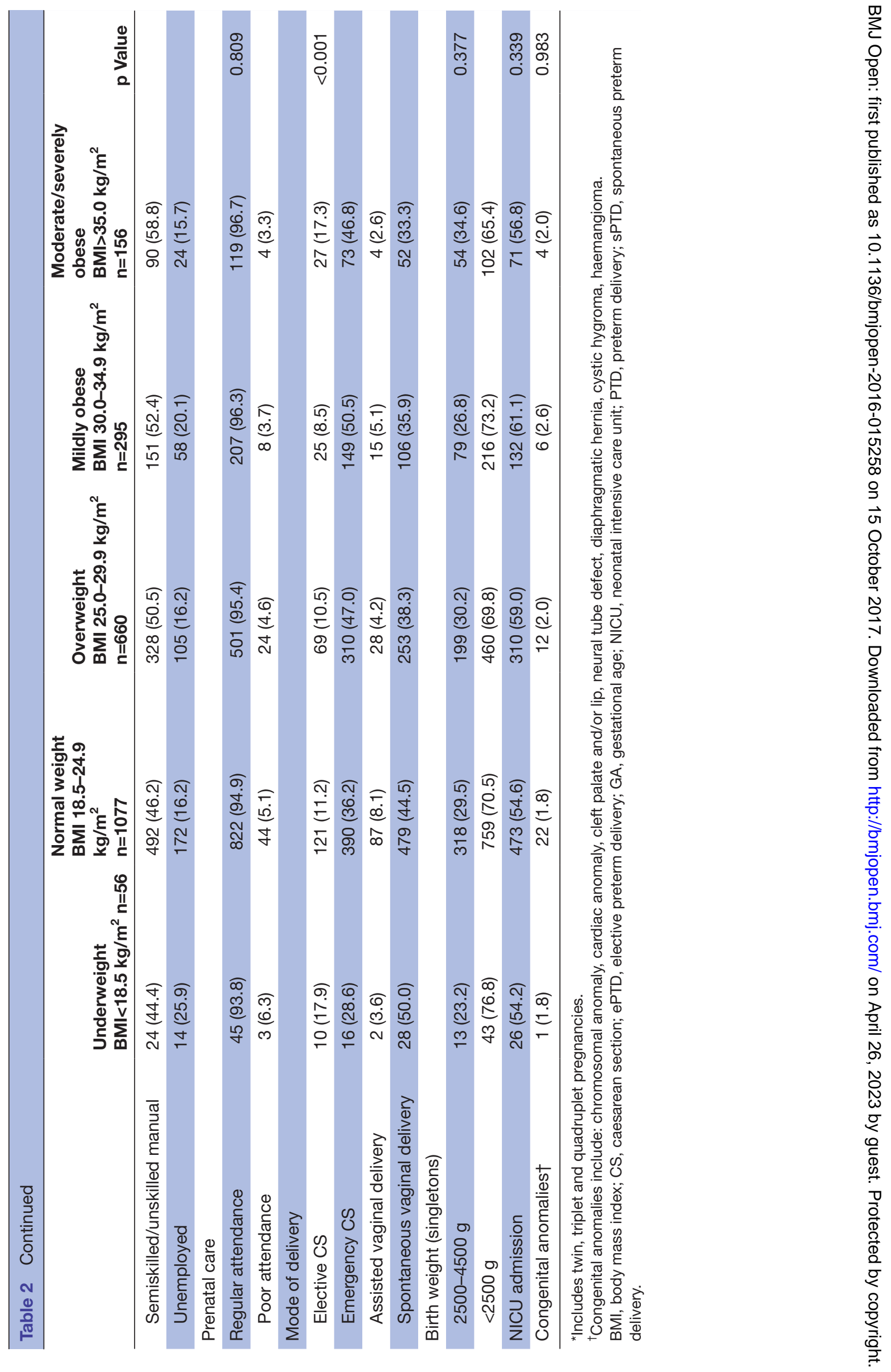


Table 3 Adjusted OR (aOR, 95\% Cls) for the association of SPTD and ePTD and maternal body mass index stratified by parity and number of fetuses in the index pregnancy, with normal weight as reference category

\begin{tabular}{|c|c|c|c|c|c|c|c|c|}
\hline & \multicolumn{2}{|c|}{$\begin{array}{l}\text { Underweight } \mathrm{BMI}<18.5 \\
\mathrm{~kg} / \mathrm{m}^{2}\end{array}$} & \multicolumn{2}{|c|}{$\begin{array}{l}\text { Overweight BMI 25.0- } \\
29.9 \mathrm{~kg} / \mathrm{m}^{2}\end{array}$} & \multicolumn{2}{|c|}{$\begin{array}{l}\text { Mildly obese BMI } \\
30.0-34.9 \mathrm{~kg} / \mathrm{m}^{2}\end{array}$} & \multicolumn{2}{|c|}{$\begin{array}{l}\text { Moderate/severely obese } \\
\text { BMI }>35.0 \mathrm{~kg} / \mathrm{m}^{2}\end{array}$} \\
\hline & aOR & $95 \% \mathrm{Cl}$ & aOR & $95 \% \mathrm{Cl}$ & aOR & $95 \% \mathrm{Cl}$ & aOR & $95 \% \mathrm{Cl}$ \\
\hline \multicolumn{9}{|l|}{ All women* } \\
\hline All PTD & 1.4 & (1.08 to 2.0 ) & 1.07 & (0.9 to 1.2 ) & 1.1 & (0.9 to 1.3 ) & 1.3 & (1.04 to 1.7 ) \\
\hline sPTD & 1.5 & (1.04 to 2.3 ) & 0.9 & (0.8 to 1.1$)$ & 0.9 & (0.7 to 1.2$)$ & 1.3 & (0.9 to 1.9 ) \\
\hline ePTD & 1.4 & (0.8 to 2.4 ) & 1.1 & (0.9 to 1.3 ) & 1.2 & (0.9 to 1.4 ) & 1.3 & (1.05 to 1.7 ) \\
\hline \multicolumn{9}{|l|}{ Nulliparas $†$} \\
\hline All PTD & 1.4 & (0.9 to 2.1 ) & 1.07 & (0.8 to 1.3 ) & 1.4 & (1.1 to 1.8 ) & 1.7 & (1.2 to 2.4 ) \\
\hline sPTD & 0.9 & (0.5 to 1.8$)$ & 1.06 & (0.8 to 1.3 ) & 1.5 & (1.08 to 2.3 ) & 2.8 & (1.7 to 4.4 ) \\
\hline ePTD & 1.8 & (1.04 to 3.4 ) & 1.07 & (0.8 to 1.3 ) & 1.3 & (0.9 to 1.8 ) & 1.2 & (0.7 to 1.9 ) \\
\hline \multicolumn{9}{|c|}{ Multiparas $†$} \\
\hline All PTD & 1.6 & (1.04 to 2.6 ) & 1.05 & (0.9 to 1.2 ) & 0.9 & (0.8 to 1.2$)$ & 1.3 & (0.9 to 1.7 ) \\
\hline sPTD & 2.2 & (1.3 to 3.8 ) & 0.9 & (0.8 to 1.2 ) & 0.8 & (0.6 to 1.1$)$ & 0.9 & (0.6 to 1.5 ) \\
\hline ePTD & 1.01 & (0.4 to 2.4 ) & 1.1 & (0.9 to 1.4 ) & 1.09 & (0.8 to1.4) & 1.4 & (1.02 to 1.9 ) \\
\hline \multicolumn{9}{|l|}{ Singleton $\ddagger$} \\
\hline All PTD & 1.5 & (1.1 to 2.1 ) & 1.09 & (0.9 to 1.2$)$ & 1.2 & (1.0 to 1.4 ) & 1.5 & (1.2 to 1.8 ) \\
\hline sPTD & 1.6 & (1.0 to 2.4 ) & 0.9 & (0.8 to 1.1 ) & 0.9 & (0.7 to 1.3 ) & 1.4 & (1.01 to 2.1 ) \\
\hline ePTD & 1.5 & (0.9 to 2.6 ) & 1.1 & (0.9 to 1.4 ) & 1.2 & (0.9 to 1.5$)$ & 1.4 & (1.1 to 1.8 ) \\
\hline \multicolumn{9}{|l|}{ Multiplesł } \\
\hline All PTD & 0.6 & (0.1 to 2.8 ) & 1.03 & (0.7 to 1.5 ) & 0.7 & (0.4 to 1.3 ) & 0.7 & (0.3 to 1.6 ) \\
\hline sPTD & - & - & 0.8 & (0.3 to 2.1 ) & 0.3 & (0.09 to 1.2$)$ & 0.4 & (0.1 to 1.7 ) \\
\hline ePTD & 0.9 & (0.2 to 3.9 ) & 0.9 & (0.6 to 1.5 ) & 0.9 & (0.5 to 1.7$)$ & 0.6 & (0.2 to 1.7$)$ \\
\hline
\end{tabular}

${ }^{*}$ Adjusted for maternal age, nativity, occupation, smoking status, parity, attendance to antenatal care, multiples, congenital anomalies. ${ }^{\dagger}$ Adjusted for maternal age, nativity, occupation, smoking status, attendance to antenatal care, multiples.

${ }^{\ddagger}$ Adjusted for maternal age, nativity, maternal occupation, smoking status, parity and attendance to antenatal care.

BMI, body mass index; ePTD, elective preterm delivery; PTD, preterm delivery; sPTD, spontaneous preterm delivery.

\section{DISCUSSION}

This large observational study confirms an association between maternal body weight and PTD. The study shows, however, that the relationship between BMI categories and PTD is more complex than hitherto described. We found that SPTD is associated with obesity in nulliparas, ePTD is associated with obesity in multiparas and obesity does not influence the risk of PTD, either SPTD or ePTD, in multiple pregnancies. In addition, we found that being underweight increased the risk of ePTD in nulliparas and increased the risk of sPTD in multiparas, but did not influence the risk of PTD, either SPTD or ePTD, in multiples. As parity and plurality are not modifiable risk factors, the net effect on the rates of PTD is dependent on the balance between the two extremes of the BMI range, underweight and obesity. Thus, while demonstrating an independent association between non-optimal BMI and adverse pregnancy outcomes, our study suggests that more research is needed into understanding the pathophysiological pathways that lead to SPTD, especially in obese women. At the same time, this study suggests that more effective strategies are needed for reduction in medically indicated PTD and optimisation of evidence-based interventions for pregnancy complications contributing to ePTD. The new information we provide may be helpful in designing targeted future interventions intended to prevent PTD.

In a recent study evaluating the risk factors for spontaneous and provider-initiated preterm births, it was shown that the effect of maternal complications on preterm birth varied between spontaneous and provider-initiated births, as well as among different countries. ${ }^{31}$ While exploring one step further, the present findings concur showing that this relationship is modulated by maternal BMI.

Among preterm deliveries, the underweight and socially disadvantaged women were less likely, while obese women, who have higher medical risks, were more likely, to have an ePTD. Although we have not explored the cause of ePTD, from our analyses that controlled for fetal aetiologies, it can be inferred that ePTD may have had medical indications, such as pregnancy complications. Evidence suggests that hypertensive disorders of pregnancy including chronic hypertension and pre-eclampsia/eclampsia increase twofold to fivefold the risk of provider-initiated PTD. ${ }^{31}$ There appears to be a linear, 'dose-dependent' relationship between obesity in 
pregnancy and the risk of pre-eclampsia, possibly mediated through insulin resistance and dyslipidaemic effects on the cardiovascular system. ${ }^{32-35}$ High BMI is associated with increased risk of pre-eclampsia in both nulliparous and multiparous women. ${ }^{32}{ }^{36}$ Thus, the increased risk of ePTD in nulliparas from our study may be due, at least in part, to higher background rates of pre-eclampsia in these women. In a study of the national registry of Scotland, a similar increased risk of ePTD occurred in obese nulliparous women. In that study, $40 \%$ of the obese nulliparous women who had an EPTD had been diagnosed with pre-eclampsia, compared with $2.6 \%$ incidence of pre-eclampsia in the remainder of the population studied. ${ }^{37}$ The positive association between obesity and ePTD in nulliparas that maintained after adjustment for sociodemographic characteristics, pre-eclampsia and other hypertensive disorders in the study from Scotland ${ }^{37}$ and a large Chinese study, ${ }^{38}$ contrasts with findings from the Danish National Birth Cohort. In the latter, when obesity-related diseases were accounted for, no excess risk of ePTD was seen in obese women. ${ }^{39}$ Other studies analysing the relationship between BMI and ePTD did not find an overall association. ${ }^{40}$ Variations in sample sizes (from less than 3000 women to more than 350000 women) and the fact that data for nulliparous and multiparous women were pooled may explain the discrepancies between studies.

The present study provides new insights into the uncertainty around the relationship between obesity in pregnancy and the risk of sPTD. While we found an increase in the risk of SPTD in nulliparous women with increasing BMI, Smith et al found a decreased risk of SPTD in a pooled cohort of nulliparous women. When stratified by BMI categories, the authors observed the association in overweight and mildly obese but not in moderate and severely obese women. ${ }^{37}$ The probable explanation for this inconsistency is that the information on BMI was self-reported, and the time of assessment was pooled from various resources.

In contrast, a recent systematic review and meta-analysis found that the risk of SPTD did not differ among overweight, obese and very obese women. ${ }^{5}$ This meta-analysis, however, analysed the pooled data for multiparous and nulliparous patients, in studies with wide heterogeneity of design and analytical measures. For instance, the vast majority of the studies assessed BMI by self-reporting, did not report the timing of BMI measurements and had small sample sizes. Thus, it is important that future studies clarify the contribution of artefactual differences owing to measurement in evaluation of the relationship between PTD and obesity.

The association between PTD and parity has been previously explored, yielding mixed results. ${ }^{14}$ Two largescale retrospective cohort studies found that obese nulliparas were at increased risk of extreme preterm delivery and elective preterm birth, whereas obese multiparas were not. ${ }^{37}{ }^{41}$ Several other studies reported increased rates of PTD, low birth weight and neonatal mortality among nulliparas, particularly when women were young. ${ }^{42-45}$ A recent meta-analysis of the association between parity and preterm birth found only a weak association between parity $\geq 3$ and the risk of preterm birth, but failed to demonstrate a dose-response relationship for parity $\geq 5 .{ }^{46}$ The lack of change in risk of preterm birth with increasing parity suggests confounders that have not been captured. The present study suggests that maternal BMI is a covariate that has the potential to alter these findings by changing the magnitude of the association between parity and preterm birth and should be considered in future studies.

Our study reports, unsurprisingly, a different baseline risk for prematurity in multiple pregnancies as compared with singleton pregnancies $(60 \%$ vs $5 \%)$. Consistent with other reports, we show that PTD in multiples is predominantly provider-initiated preterm birth..$^{22}$ These findings suggest that more aggressive management of multiples may be associated with changes in birth outcomes in this population. ${ }^{47}$ We show, however, that obesity-attributable adverse birth outcomes are lower in multiples compared with singletons. The fact that there was no association between maternal BMI and the risk of ePTD points to a more intensive prenatal care utilisation in these patients regardless of body weight, which may lead to increase in medical interventions in the management of multiples, and respectively, more preterm births.

Numerous studies have explored causal inference between social determinants and pregnancy health. ${ }^{48-50}$ Birth outcomes such as PTD are widely accepted key indicators of population health, social development and economic change. ${ }^{51}$ Wide variations in the prevalence of PTD observed between and within countries, ${ }^{52-54}$ including developed nations, ${ }^{55}{ }^{56}$ may be explained, at least in part, by the dynamic interplay between contextual, societal determinants of health and individual level biological, behavioural and psychosocial factors. ${ }^{12}{ }^{57}$ Our study supports these assumptions, the analyses demonstrating that maternal nativity, smoking and occupation, as a proxy for level of education and income, are independent factors associated with SPTD. ${ }^{58}$ While ethnic disparities, maternal health behaviours and psychosocial stress contribute to differential pregnancy outcomes, socioeconomic disparities in birth outcomes are additionally pervasive. ${ }^{11-1360}$

\section{Strengths and limitations of the study}

This is the first study, to our knowledge, to analyse the risk of PTD stratifying by BMI category, parity and type of pregnancy, factors that each individually are known health determinants of PTD. The vast majority of prior studies include both variables either as confounders or perform the analyses in selected populations. Analysis of a large, nationally representative cohort of women who delivered in a single maternity hospital over a short time frame is another major strength of this study. ${ }^{26}$ In addition, all women were offered sonographic dating at the ultrasound department at their first antenatal visit. The precise estimation of gestational age is paramount for the 
accurate diagnosis of preterm birth. This has implications for evaluation of the statistical indicators that gauge the health status of populations and research, and for the management of the pregnancy and newborn infants, ${ }^{61}$ gestational age being a proxy for the extent of fetal development, chances for survival at birth, and the likelihood of developing complications. ${ }^{62}$

Furthermore, BMI was calculated based on the measurement of maternal weight and height at the first prenatal visit and not from maternal self-report, which is known to introduce under-reporting bias and to exaggerate the epidemiological risks of obesity. ${ }^{63-65}$ This translates in increased accuracy and reliability of our data. Statistical analysis has adjusted for confounding variables which is critical for any epidemiological study on PTD ${ }^{48}$ Although the study was retrospective, data extracted from a single tertiary care centre assured consistent prenatal care with regular antenatal clinic visits, ultrasound assessment for cervical assessment and monitoring of fetal growth, and standardised, high-quality recording of demographic and clinical data for all patients.

Despite its strengths, our study has limitations. First, the overall rate of PTD was small and resulted in a small sample size for the severely obese women and the need to collapse the BMI moderate and severe categories for meaningful statistical comparisons. However, the PTD rate in our study is comparable with other European countries and may reflect contextual differences such as advances in healthcare, affordability and accessibility to specialised prenatal care. Thus, our results, while representative of western populations, may not be reproducible in developing countries. Additional studies with higher sample sizes of class III obesity are warranted to confirm our findings for severe obesity. Second, we report on BMI at the first prenatal visit in the maternity unit, in contrast with the vast majority of previous studies reporting on pre-pregnancy BMI. However, a potential bias that may be introduced by the time of the onset of prenatal care and BMI recording in pregnancy is unlikely for this study for several reasons. Women from our cohort received prenatal care through the prenatal clinics of the maternity unit from the first trimester of pregnancy. Together with BMI measurement and dating scan, this represents the standard of prenatal care in Ireland. In addition, we controlled in the analyses for the late bookers and those women with poor attendance (less than $0.2 \%$ of the population), as it is well known that late initiation of antenatal care is associated with PTD. Furthermore, previous reports, including from our research group, suggest minimal weight gain $(<2.0 \mathrm{~kg})$ or no increase in average maternal weight or body composition before 18 weeks' gestation. ${ }^{25} 3066$ As such, our measurements of body weight in the first trimester reflect with accuracy the baseline BMI in pregnancy. Third, no detailed information on obstetrical history was available for this study. Therefore, we were not able to appreciate the rate of recurrent second trimester miscarriage or preterm birth in our cohort and its relationship with maternal body composition. In addition, our sample of multiples was relatively small, which may potentially explain why no association was observed between BMI and PTD multiples. However, the decision of delivery in multiples is frequently a trade-off between benefits and harm, being based on chorionicity, complications of pregnancy and assessment of fetal well-being. Hence, decisions based on clinical protocols and guidelines for time of delivery in multiples may as well explain the lack of association between BMI and PTD in this group. Furthermore, we had no information on the indications of ePTD. However, it is likely that pregnancy complications of either maternal or fetal aetiology may have decided on optimal time of delivery. We also acknowledge that a relatively small sample of multiples was included in this study, which may contribute to explain the lack of association observed between BMI and PTD in this group.

\section{Significance and implications for clinical practice}

In summary, our study highlights the complex nature of the influence of maternal BMI on pregnancy outcomes. Although our study does not prove causality, the present findings suggest that shared factors, such as maternal and pregnancy characteristics, may modulate the obesity-attributable risk of PTD. We found that parity has a complex influence on the relationship between PTD, either spontaneous or elective, and maternal BMI and that obesity-attributable adverse outcomes such as SPTD or ePTD were lower in multiple pregnancies compared with singleton pregnancies.

As PTD is a key determinant of perinatal morbidity and mortality, our study indicates that strategies for reducing PTD rates should focus on underweight women throughout pregnancy and preventing maternal obesity at the onset of pregnancy. Provision of adequate obstetric care, especially to the socially disadvantaged, corroborated with well-balanced decision-making on optimal timing for delivery in high-risk pregnancies could improve pregnancy outcomes. Most importantly, our study points to a largely neglected risk factor for preterm birth that is maternal BMI. While various national and international bodies, including the WHO, have published guidelines for antenatal care in obese women, no recommendations include clear guidance for management of maternal obesity. ${ }^{67-69}$ Most of the interventions to date target the preconception period, while the level of interventions and their efficacy during pregnancy is less clear. Thus, while there is growing evidence showing that maternal obesity may influence pregnancy outcomes, additional studies should decipher in depth this complex relationship in order to develop targeted and efficient interventions that would improve perinatal outcomes in women with non-optimal BMI.

Acknowledgements We thank Ms Emma McNamee (IT Department, Coombe Women and Infants University Hospital Dublin) for data retrieval.

Contributors AV and MT: conceived and designed the research; AV: analysed the data and wrote the manuscript with input from ND and MT; AM: prepared the initial 
data set, defined and classified the variables; SS: provided clinical governance and oversaw data collection. All authors provided feedback on the manuscript drafts and approved the final version.

\section{Competing interests None declared.}

Patient consent Detail has been removed from this case description/these case descriptions to ensure anonymity. The editors and reviewers have seen the detailed information available and are satisfied that the information backs up the case the authors are making.

Ethics approval Coombe Women and Infants University Hospital Research Ethics Committee (ref 004-013).

Provenance and peer review Not commissioned; externally peer reviewed.

Data sharing statement № additional data available.

Open Access This is an Open Access article distributed in accordance with the Creative Commons Attribution Non Commercial (CC BY-NC 4.0) license, which permits others to distribute, remix, adapt, build upon this work non-commercially, and license their derivative works on different terms, provided the original work is properly cited and the use is non-commercial. See: http://creativecommons.org/ licenses/by-nc/4.0/

(c) Article author(s) (or their employer(s) unless otherwise stated in the text of the article) 2017. All rights reserved. No commercial use is permitted unless otherwise expressly granted.

\section{REFERENCES}

1. Institute of Medicine. Leading health indicators for healthy people 2020: letter report. Washington (DC): The National Academies Press, 2011.

2. Blencowe $\mathrm{H}$, Cousens $\mathrm{S}$, Oestergaard $\mathrm{MZ}$, et al. National, regional, and worldwide estimates of preterm birth rates in the year 2010 with time trends since 1990 for selected countries: a systematic analysis and implications. Lancet 2012;379:2162-72.

3. Lawn JE, Gravett MG, Nunes TM, et al. Global report on preterm birth and stillbirth (1 of 7): definitions, description of the burden and opportunities to improve data. BMC Pregnancy Childbirth 2010;10(Suppl 1):S1.

4. Honest $\mathrm{H}$, Bachmann LM, Ngai C, et al. The accuracy of maternal anthropometry measurements as predictor for spontaneous preterm birth--a systematic review. Eur J Obstet Gynecol Reprod Biol 2005;119:11-20.

5. McDonald SD, Han Z, Mulla S, et al. Overweight and obesity in mothers and risk of preterm birth and low birth weight infants: systematic review and meta-analyses. BMJ 2010;341:c3428.

6. Schaaf JM, Liem SM, Mol BW, et al. Ethnic and racial disparities in the risk of preterm birth: a systematic review and meta-analysis. Am J Perinatol 2013;30:433-50.

7. Shah PS, Balkhair T, Ohlsson A, et al. Intention to become pregnant and low birth weight and preterm birth: a systematic review. Matern Child Health J 2011;15:205-16.

8. Leitich $\mathrm{H}$, Bodner-Adler B, Brunbauer $\mathrm{M}$, et al. Bacterial vaginosis as a risk factor for preterm delivery: a meta-analysis. Am J Obstet Gynecol 2003;189:139-47.

9. Carolan M, Frankowska D. Advanced maternal age and adverse perinatal outcome: a review of the evidence. Midwifery 2011;27:793-801.

10. Clausson B, Cnattingius S, Axelsson O. Preterm and term births of small for gestational age infants: a population-based study of risk factors among nulliparous women. Br J Obstet Gynaecol 1998;105:1011-7.

11. Blumenshine P, Egerter S, Barclay CJ, et al. Socioeconomic disparities in adverse birth outcomes: a systematic review. Am J Prev Med 2010;39:263-72.

12. Littleton $\mathrm{HL}$, Bye $\mathrm{K}$, Buck $\mathrm{K}$, et al. Psychosocial stress during pregnancy and perinatal outcomes: a meta-analytic review. $J$ Psychosom Obstet Gynaecol 2010;31:219-28.

13. Shah NR, Bracken MB. A systematic review and meta-analysis of prospective studies on the association between maternal cigarette smoking and preterm delivery. Am J Obstet Gynecol 2000;182:465-72.

14. Shah PS. Parity and low birth weight and preterm birth: a systematic review and meta-analyses. Acta Obstet Gynecol Scand 2010;89:862-75.

15. Han Z, Lutsiv O, Mulla S, et al. Maternal height and the risk of preterm birth and low birth weight: a systematic review and metaanalyses. J Obstet Gynaecol Can 2012;34:721-46.
16. Han Z, Mulla S, Beyene J, et al. Maternal underweight and the risk of preterm birth and low birth weight: a systematic review and metaanalyses. Int J Epidemiol 2011;40:65-101.

17. Torloni MR, Betrán AP, Daher S, et al. Maternal BMI and preterm birth: a systematic review of the literature with meta-analysis. $J$ Matern Fetal Neonatal Med 2009;22:957-70.

18. Shaw GM, Wise PH, Mayo J, et al. Maternal prepregnancy body mass index and risk of spontaneous preterm birth. Paediatr Perinat Epidemiol 2014;28:302-11.

19. Martin JA, Hamilton BE, Osterman MJ, et al. Births: final data for 2012. Natl Vital Stat Rep 2013;62:1-68.

20. Stock S, Norman J. Preterm and term labour in multiple pregnancies. Semin Fetal Neonatal Med 2010;15:336-41.

21. Ananth CV, Chauhan SP. Epidemiology of twinning in developed countries. Semin Perinatol 2012;36:156-61.

22. Lucovnik M, Blickstein I, Verdenik I, et al. Maternal obesity in singleton versus twin gestations: a population-based matched casecontrol study. J Matern Fetal Neonatal Med 2015;28:623-5.

23. Salihu HM, Lynch O, Alio AP, et al. Obesity subtypes and risk of spontaneous versus medically indicated preterm births in singletons and twins. Am J Epidemiol 2008;168:13-20.

24. Siega-Riz AM. Determinants prepregnancy obesity: consequences and solutions. Adv Nutr 2012;3:105-7.

25. Rasmussen KM, Yaktine AL. Weight gain during pregnancy: reexamining the guidelines: The National Academy Press, 2009.

26. McKeating A, Maguire PJ, Daly N, et al. Trends in maternal obesity in a large university hospital 2009-2013. Acta Obstet Gynecol Scand 2015;94:969-75.

27. Turner MJ, Layte R. Obesity levels in a national cohort of women 9 months after delivery. Am J Obstet Gynecol 2013;209:e121-7.

28. Kent E, O'Dwyer V, Fattah C, et al. Correlation between birth weight and maternal body composition. Obstet Gynecol 2013;121:46-50.

29. Lynch CM, Sexton DJ, Hession M, et al. Obesity and mode of delivery in primigravid and multigravid women. Am J Perinatol 2008;25:163-7.

30. Fattah C, Farah N, Barry SC, et al. Maternal weight and body composition in the first trimester of pregnancy. Acta Obstet Gynecol Scand 2010;89:952-5.

31. Morisaki N, Togoobaatar G, Vogel JP, et al. WHO Multicountry Survey on Maternal and Newborn Health Research Network. Risk factors for spontaneous and provider-initiated preterm delivery in high and low human development Index countries: a secondary analysis of the world health organization multicountry survey on maternal and newborn health. BJOG 2014;121(Suppl 1):101-9.

32. Vinturache A, Moledina N, McDonald S, et al. Pre-pregnancy Body Mass Index (BMI) and delivery outcomes in a canadian population. BMC Pregnancy Childbirth 2014;14:422.

33. Salihu HM, De La Cruz C, Rahman S, et al. Does maternal obesity cause preeclampsia? A systematic review of the evidence. Minerva Ginecol 2012;64:259-80.

34. Hauth JC, Clifton RG, Roberts JM, et al. Maternal insulin resistance and preeclampsia. Am J Obstet Gynecol 2011;204:327:e321-6.

35. Wolf M, Hubel CA, Lam C, et al. Preeclampsia and future cardiovascular disease: potential role of altered angiogenesis and insulin resistance. J Clin Endocrinol Metab 2004;89:6239-43.

36. Duckitt K, Harrington D. Risk factors for pre-eclampsia at antenatal booking: systematic review of controlled studies. BMJ 2005;330:565.

37. Smith GC, Shah I, Pell JP, et al. Maternal obesity in early pregnancy and risk of spontaneous and elective preterm deliveries: a retrospective cohort study. Am J Public Health 2007;97:157-62.

38. Wang T, Zhang J, Lu X, et al. Maternal early pregnancy body mass index and risk of preterm birth. Arch Gynecol Obstet 2011;284:813-9.

39. Nohr EA, Bech $\mathrm{BH}$, Vaeth $\mathrm{M}$, et al. Obesity, gestational weight gain and preterm birth: a study within the danish national birth cohort. Paediatr Perinat Epidemiol 2007;21:5-14.

40. Hendler I, Goldenberg RL, Mercer BM, et al. The preterm prediction study: association between maternal body mass index and spontaneous and indicated preterm birth. Am J Obstet Gynecol 2005;192:882-6.

41. Cnattingius S, Villamor E, Johansson S, et al. Maternal obesity and risk of preterm delivery. JAMA 2013;309:2362-70.

42. Gibbs CM, Wendt A, Peters S, et al. The impact of early age at first childbirth on maternal and infant health. Paediatr Perinat Epidemiol 2012;26(Suppl 1):259-84.

43. Scholl TO, Hediger ML, Huang J, et al. Young maternal age and parity. Influences on pregnancy outcome. Ann Epidemiol 1992;2:565-75.

44. Conde-Agudelo A, Belizán JM, Lammers C. Maternal-perinatal morbidity and mortality associated with adolescent pregnancy 
in Latin America: cross-sectional study. Am J Obstet Gynecol 2005:192:342-9.

45. Chen XK, Wen SW, Fleming N, et al. Teenage pregnancy and adverse birth outcomes: a large population based retrospective cohort study. Int J Epidemiol 2007;36:368-73.

46. Kozuki N, Lee AC, Silveira MF, et al. The associations of parity and maternal age with small-for-gestational-age, preterm, and neonatal and infant mortality: a meta-analysis. BMC Public Health 2013;13(Suppl 3):S2.

47. Kogan MD, Alexander GR, Kotelchuck M, et al. Trends in twin birth outcomes and prenatal care utilization in the United States, 19811997. JAMA 2000;284:335-41.

48. Kim D, Saada A. The social determinants of infant mortality and birth outcomes in Western developed nations: a cross-country systematic review. Int J Environ Res Public Health 2013;10:2296-335.

49. Dominguez TP. Race, racism, and racial disparities in adverse birth outcomes. Clin Obstet Gynecol 2008;51:360-70.

50. Fiscella K. Racial disparity in infant and maternal mortality: confluence of infection, and microvascular dysfunction. Matern Child Health J 2004;8:45-54.

51. Conley D, Springer KW. Welfare state and infant mortality. AJS 2001;107:768-807.

52. Dolatian M, Mirabzadeh A, Forouzan AS, et al. Preterm delivery and psycho-social determinants of health based on World Health Organization model in Iran: a narrative review. Glob J Health Sci 2012;5:52-64.

53. Grjibovski AM, Bygren LO, Yngve A, et al. Large social disparities in spontaneous preterm birth rates in transitional Russia. Public Health 2005;119:77-86.

54. Bahadori M, Sanaeinasab H, Ghanei M, et al. The Social Determinants of Health (SDH) in Iran: a systematic review article. Iran J Public Health 2015;44:728-41.

55. Field D, Draper ES, Fenton A, et al. Rates of very preterm birth in Europe and neonatal mortality rates. Arch Dis Child Fetal Neonatal Ed 2009;94:F253-F256.

56. Macinko JA, Shi L, Starfield B. Wage inequality, the health system, and infant mortality in wealthy industrialized countries, 1970-1996. Soc Sci Med 2004;58:279-92.
57. Nabukera SK, Wingate MS, Owen J, et al. Racial disparities in perinatal outcomes and pregnancy spacing among women delaying initiation of childbearing. Matern Child Health J 2009;13:81-9.

58. Niedhammer I, Murrin C, O'Mahony D, et al. Explanations for social inequalities in preterm delivery in the prospective Lifeways cohort in the Republic of Ireland. Eur J Public Health 2012;22:533-8.

59. Kelley M, Rubens CE. GAPPS Review Group. Global report on preterm birth and stillbirth (6 of 7): ethical considerations. BMC Pregnancy Childbirth 2010;10(Suppl 1):S6.

60. Littleton HL, Breitkopf CR, Berenson AB. Correlates of anxiety symptoms during pregnancy and association with perinatal outcomes: a meta-analysis. Am J Obstet Gynecol 2007;196:424-32.

61. Alexander GR, Allen MC. Conceptualization, measurement, and use of gestational age. I. Clinical and public health practice. J Perinatol 1996;16:53-9.

62. Alexander GR, Tompkins ME, Cornely DA. Gestational age reporting and preterm delivery. Public Health Rep 1990;105:267-75.

63. Bodnar LM, Siega-Riz AM, Simhan HN, et al. The impact of exposure misclassification on associations between prepregnancy BMI and adverse pregnancy outcomes. Obesity 2010;18:2184-90.

64. Nieto-García FJ, Bush TL, Keyl PM. Body mass definitions of obesity: sensitivity and specificity using self-reported weight and height. Epidemiology 1990;1:146-52.

65. Brunner Huber LR. Validity of self-reported height and weight in women of reproductive age. Matern Child Health J 2007;11:137-44.

66. O'Higgins AC, Doolan A, Mullaney L, et al. The relationship between gestational weight gain and fetal growth: time to take stock? $J$ Perinat Med 2014;42:409-15.

67. Schumann NL, Brinsden H, Lobstein T. A review of national health policies and professional guidelines on maternal obesity and weight gain in pregnancy. Clin Obes 2014;4:n/a-208.

68. World Health Organization. Obesity: preventing and managing the global epidemic: Report of a WHO consultation, 2000:0512-3054.

69. American College of Obstetricians and Gynecologists. ACOG Committee opinion no. 549: obesity in pregnancy. Obstet Gynecol 2013;121:213-7. 